\title{
Real-time flood inundation forecasting and mapping for key railway infrastructure: a UK case study
}

\author{
Alexandra T. Murphy ${ }^{1, a}$, Ben Gouldby ${ }^{1}$, Steven J. Cole ${ }^{2}$, Robert J. Moore ${ }^{2}$ and Helen Kendall ${ }^{3}$ \\ ${ }^{1}$ HR Wallingford, Howbery Park, Wallingford, Oxfordshire, OX10 8BA, UK \\ ${ }^{2}$ Centre for Ecology \& Hydrology, Maclean Building, Crowmarsh Gifford, Wallingford, Oxfordshire, OX10 8BB, UK \\ ${ }^{3}$ Met Office, Fitzroy Road, Exeter, Devon, EX1 3PB, UK
}

\begin{abstract}
Flooding events that impede railway infrastructure can cause severe travel delays for the general public and large fines in delayed minutes for the rail industry. Early warnings of flood inundation can give more time to implement mitigation measures which help reduce cancellations, delays and fines. Initial work is reported on the development of a real-time flood inundation forecasting and mapping system for the Cowley Bridge track area near Exeter, UK. This location is on one of the main access routes to South West England and has suffered major floods in the past resulting in significant transport impacts. Flood forecasting systems in the UK mainly forecast river level/flow rather than extent and depth of flood inundation. Here, the development of a chain of coupled models is discussed that link rainfall to river flow, river level and flood extent for the rail track area relating to Cowley Bridge. Historical events are identified to test model performance in predicting inundation of railway infrastructure. The modelling system will operate alongside a series of in-situ sensors chosen to enhance the flood mapping forecasting system. Sensor data will support offline model calibration/verification and real-time data assimilation as well as monitoring flood conditions to inform track closure decisions.
\end{abstract}

\section{Introduction}

Railway track closures due to river flood inundation are costly and disruptive. An important mitigation measure is the ability to forewarn of flooding through exploiting advances in numerical weather forecasting of rainfall along with hydrological and hydraulic models of river systems so as to map the depth and extent of likely flooding out to several days.

This paper presents initial work on a prototype design for a real-time system for flood inundation forecasting to support railway track closure decision-making. The study is in association with the Remote Condition Monitoring Challenges which are part-funded by the Rail Safety Standards Board (RSSB) and Network Rail (NR). The study uses the Cowley Bridge track area near Exeter, on the mainline from London to south west England, as a case study experiencing serious flooding leading to track closures in recent years. Historical records at times of track closure are identified to support an offline trial of the real-time system as a precursor to future real-time use. Deployment of in-situ sensors are also considered to support model calibration, validation and real-time data assimilation as well as to monitor flood conditions to inform decision-making on track closure.

Current approaches to flood forecasting in the UK tend to focus on forecasting river levels and flow. Whilst these can provide useful indicators of imminent flooding of railway infrastructure, additional and potentially complex translation of the information is required by decision-makers. It may not be obvious whether the forecast river levels are sufficient to flood track infrastructure, particularly if this is located in topographically complex areas. Two-dimensional hydraulic models of flood inundation have been in widespread use for flood mapping purposes for well-over a decade. When provided with appropriate data they have been shown to be capable of producing the dominant characteristics of floods in terms of water depth and velocity across the inundated area. They have therefore been used for simulating historical flood events, flood risk analysis and flood mapping. There is however, in principle, no reason why these models cannot be used in real-time for flood mapping purposes. In the past, one of the reasons limiting the uptake of these models in realtime has been excessive computational times. With significant increases in computational resources and new coding techniques now readily accessible this challenge has diminished to a certain degree.

The use of these models in real-time can aid decisionmakers by providing forecasts of flood extents and depths. These forecasts provide a more robust evidence base for guiding mitigating measures including track closure decisions. The advance warning enables proactive mitigation and planning measures to be applied such as timetable adjustments and replacement transport arrangements.

\footnotetext{
a Corresponding author: a.murphy@hrwallingford.com
} 


\section{The flood map forecasting chain}

Current operational flood forecasting systems in the UK generally forecast river level and/or flow rather than extent and depth of flood inundation. Here, a chain of coupled models is developed that links rainfall forecasts to river flow, river level and flood extent. The chain is to be initially trialled through off-line coupling and testing on historical case studies whilst also planning for potential real-time application.

Models with countrywide coverage are used, where appropriate, to facilitate operational implementation and transfer to other areas of interest beyond the initial trial area of Cowley Bridge. Where detailed inundation models are required, re-use or adaption of existing models is considered first.

The forecasting chain consists of:

-Rainfall forecast products (deterministic and ensemble forms),

-Hydrological model (river flow and surface runoff),

-Hydrodynamic flood inundation model (river levels and flood extents).

The modelling system operates alongside a series of in-situ sensors and observations, which benefit a flood inundation forecasting system in the following ways.

- Offline calibration and verification of the flood mapping system,

-Real-time data assimilation, where measurements from sensors are used as input to correct and improve the forecasts,

-Use of real-time measurements to provide information on flood conditions, which can directly inform track closure decisions.
The three modelling components are considered in more detail in the following subsections along with details of any relevant observation data that support the system.

\subsection{Rainfall forecast and observation products}

UK-wide rainfall observation and forecast products developed by the Met Office can be made available for use in real-time flood mapping. Raingauge observations made by other operating agencies, such as the Environment Agency (EA) and Natural Resources Wales (NRW), are also available for use.

The Met Office are continually improving and upgrading their meteorological observation and forecast products. Thus, the data products used here as available over the historical casse study period will be expected to be improved upon in the future.

A major recent advance has been the move to ensemble rainfall forecasting. This is underpinned by the Met Office Global and Regional Ensemble Prediction System (MOGREPS) [1] that aims to capture uncertainty in both the forecast model formulation and the starting conditions. MOGREPS is used primarily for short-range forecasts of rainfall over the UK at $2.2 \mathrm{~km}$ resolution, but also for the whole globe up to a week ahead at $33 \mathrm{~km}$ resolution. Furthermore, the outputs are downscaled to 2 $\mathrm{km}$ and blended together with extrapolated (nowcast) radar rainfall using the Short-Term Ensemble Prediction System (STEPS) methodology [2-4].

Table 1 summarises the relevant rainfall products that are currently available. Note that for this application, the focus is on the 24-hour plus lead-time so short lead-time radar-based nowcast extrapolations are not included.

\begin{tabular}{|c|c|c|}
\hline Rainfall product & Specification & Description \\
\hline \multicolumn{3}{|l|}{ Observations } \\
\hline $\begin{array}{l}\text { HyradK Gridded Rainfall } \\
{[5,6]}\end{array}$ & 15 min totals, $1 \mathrm{~km}$ & $\begin{array}{l}\text { Used by Flood Forecasting Centre as input to national G2G } \\
\text { model. Uses radar rainfall and/or EA raingauge data. }\end{array}$ \\
\hline Radar rain-accumulation & 15 min totals, $1 \mathrm{~km}$ & $\begin{array}{l}15 \text { min total from } 5 \text { min radar data, taking advection of } \\
\text { rainfall field into account. }\end{array}$ \\
\hline $\begin{array}{l}\text { Best rainfall observation } \\
\text { real-time }\end{array}$ & $\begin{array}{l}15 \text { min totals, } 1 \mathrm{~km} \text {, } \\
\text { delayed by up to } 1 \text { hour. }\end{array}$ & $\begin{array}{l}\text { Pilot product. Applies real-time quality-control to raingauge } \\
\text { data and merges them with radar data. }\end{array}$ \\
\hline \multicolumn{3}{|l|}{ Deterministic forecasts } \\
\hline $\begin{array}{l}\text { Best Data - Forecast } \\
\text { short-range }\end{array}$ & $\begin{array}{l}15 \text { min totals to } \mathrm{T}+36 \mathrm{~h} \text {, } \\
6 \mathrm{~h} \text { update, } 2 \mathrm{~km}\end{array}$ & $\begin{array}{l}\text { Uses variable resolution NWP Model (UKV) [7]. } \\
\sim 1.5 \mathrm{~km} \text { resolution over the UK. }\end{array}$ \\
\hline $\begin{array}{l}\text { Best Data }- \text { Forecast } \\
\text { medium-range }\end{array}$ & $\begin{array}{l}1 \mathrm{~h} \text { totals to } \mathrm{T}+120 \mathrm{~h} \text {, } \\
6 \mathrm{~h} \text { update, } 2 \mathrm{~km}\end{array}$ & $\begin{array}{l}\text { Blend best/most recent NWP data available. Currently uses } \\
\text { UKV then Euro } 4 \text { ( } 4 \mathrm{~km} \text { NWP) at longer lead-times. }\end{array}$ \\
\hline \multicolumn{3}{|l|}{ Ensemble forecasts } \\
\hline $\begin{array}{l}\text { Best Data - Forecast } \\
\text { short-range ensemble }\end{array}$ & $\begin{array}{l}15 \text { min totals to } \mathrm{T}+32 \mathrm{~h} \text {, } \\
6 \mathrm{~h} \text { update, } 2 \mathrm{~km}, 24 \text { members }\end{array}$ & $\begin{array}{l}\text { Blends radar extrapolation with MOGREPS-UK } 2.2 \mathrm{~km} \\
12 \text { member ensemble. }\end{array}$ \\
\hline $\begin{array}{l}\text { Best Data }- \text { Forecast } \\
\text { medium-range ensemble }\end{array}$ & $\begin{array}{l}1 \mathrm{~h} \text { totals to } \mathrm{T}+156 \mathrm{~h}, \\
6 \mathrm{~h} \text { update, } 2 \mathrm{~km}, 24 \text { members }\end{array}$ & $\begin{array}{l}\text { Blends radar extrapolation with MOGREPS-UK } 2.2 \mathrm{~km} \\
12 \text { member ensemble out to } \sim \mathrm{T}+32 \mathrm{~h} \text {, and downscaled global } \\
\text { ensemble (MOGREPS-G) out to } 6.5 \text { days. }\end{array}$ \\
\hline
\end{tabular}

Table 1. Gridded observed and forecast rainfall products. 


\subsection{Hydrological model (G2G)}

The Grid-to-Grid Model, or G2G, is a physicalconceptual distributed hydrological model developed by the Centre for Ecology \& Hydrology in the UK [8-10]. A schematic of the model is provided in Figure 1. G2G is especially suited to simulate surface runoff and river flow over ungauged areas on account of its capability to forecast at any location across a gridded model domain. This is achieved by using spatial datasets on landscape properties - terrain, land-cover, soil and geology - in combination with gridded time-series of rainfall to shape a rainfall pattern into a river flow response over the model domain

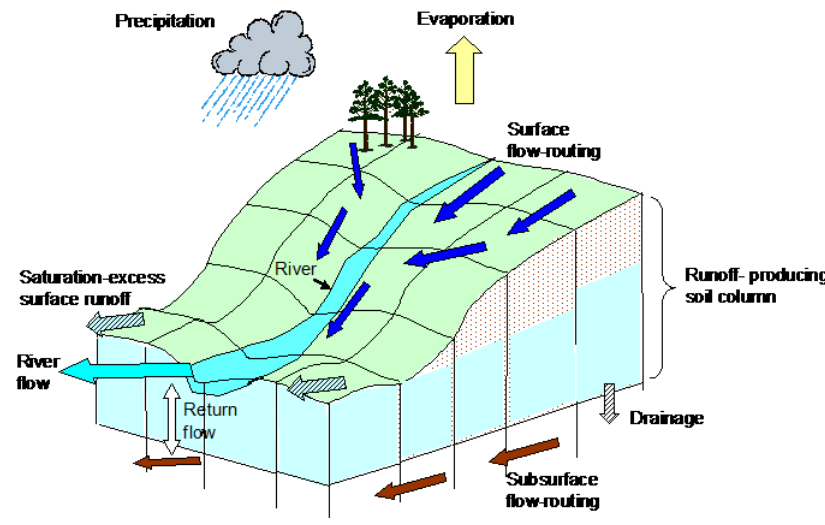

Figure 1. Schematic of the Grid-to-Grid Model.

G2G is in operational use all day, everyday, by the Flood Forecasting Centre (FFC) across England \& Wales [11] and by the Scottish Flood Forecasting Service over Scotland [12] where it underpins daily Flood Guidance Statements that provide a 5-day outlook. Within the FFC, the $\mathrm{G} 2 \mathrm{G}$ is already coupled with the deterministic and ensemble rainfall forecast models listed in Table 1, using the Met Office supercomputer to produce the hydrological ensemble outputs. This ensemble approach has been shown to have benefits for forecasting of flooding at ungauged locations and for Rapid Response Catchments [13].

G2G is currently configured to operate at a $1 \mathrm{~km}$ resolution across Britain and uses a 15 minute output time-step. This aligns to the frequency of river flow observations which can be assimilated within $\mathrm{G} 2 \mathrm{G}$ to improve forecasts. Three data assimilation techniques are used: (i) direct flow insertion allows observed flows, available up to the time the $\mathrm{G} 2 \mathrm{G}$ model is run ("timenow"), to be used instead of modelled flows to improve forecast performance at locations downstream of river gauging stations, (ii) a simple empirical state-correction scheme for the $\mathrm{G} 2 \mathrm{G}$ model is provided for forecast updating in real-time, and (iii) model simulation errors up to time now can be used to forecast future errors using an Auto-Regressive Moving Average (ARMA) errorpredictor and in turn produce an internally updated flow forecast for each gauged river location.

Observed rainfall products and river flow data can be used to calibrate and validate the G2G Model. Validation can range from assessment of the hydrological process model in isolation using only rainfall (and potential evaporation) as input to forms that include river flow data assimilation techniques and to full "forecast-mode" assessments with rainfall forecasts [13].

\subsubsection{Coupling G2G with a flood inundation model}

G2G outputs can be coupled with a flood inundation model in two ways. Firstly, the river flow boundary inputs to the flood inundation model can be provided by $\mathrm{G} 2 \mathrm{G}$. These can be at gauged river locations or at ungauged lateral inflow locations. The use of $\mathrm{G} 2 \mathrm{G}$ for providing inflows at ungauged locations is seen as particularly novel and is a natural approach to maintain a spatially coherent set of boundary inputs.

A second method of coupling is to use the surface runoff estimates from G2G as "direct" or "effective" rainfall input to the inundation model. Care is needed to only use these inputs downstream of $\mathrm{G} 2 \mathrm{G}$ river flow inputs to ensure mass balance.

\subsection{Flood inundation model}

Flood inundation is simulated in a hydrodynamic model that provides a one-dimensional (1D) representation of the river channel linked to a twodimensional (2D) representation of the floodplain. The model is built using the Innovyze software Infoworks ICM (Integrated Catchment Modelling), which uses an unstructured triangular mesh for the 2D representation. The source model is from the Environmnet Agency (2011) Exeter 2D Modelling and Mapping model update. The model solves the full 2D shallow water equations using an advanced numerical scheme. The model extent (see Figure 2) covers the River Creedy from the gauging station at Cowley to the River Exe, and the River Exe from Stafford Bridge to Trew's Weir.

Flows from G2G provide boundary condition inputs at the Cowley gauging station on the River Creedy and at Stafford Bridge on the River Exe.

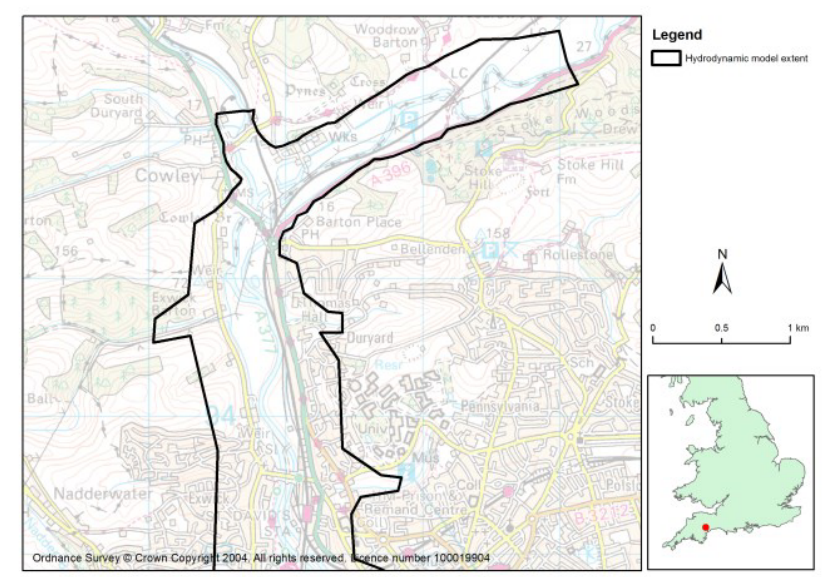

Figure 2. Map showing the extent of the inundation model at Cowley Bridge. 


\subsection{Map outputs to support decision-making}

The output from the 2D flood inundation model comprises flood depths and velocities that can be mapped. The maps provide an immediate visual indication of the impact of the forecast flood (Figure 3).
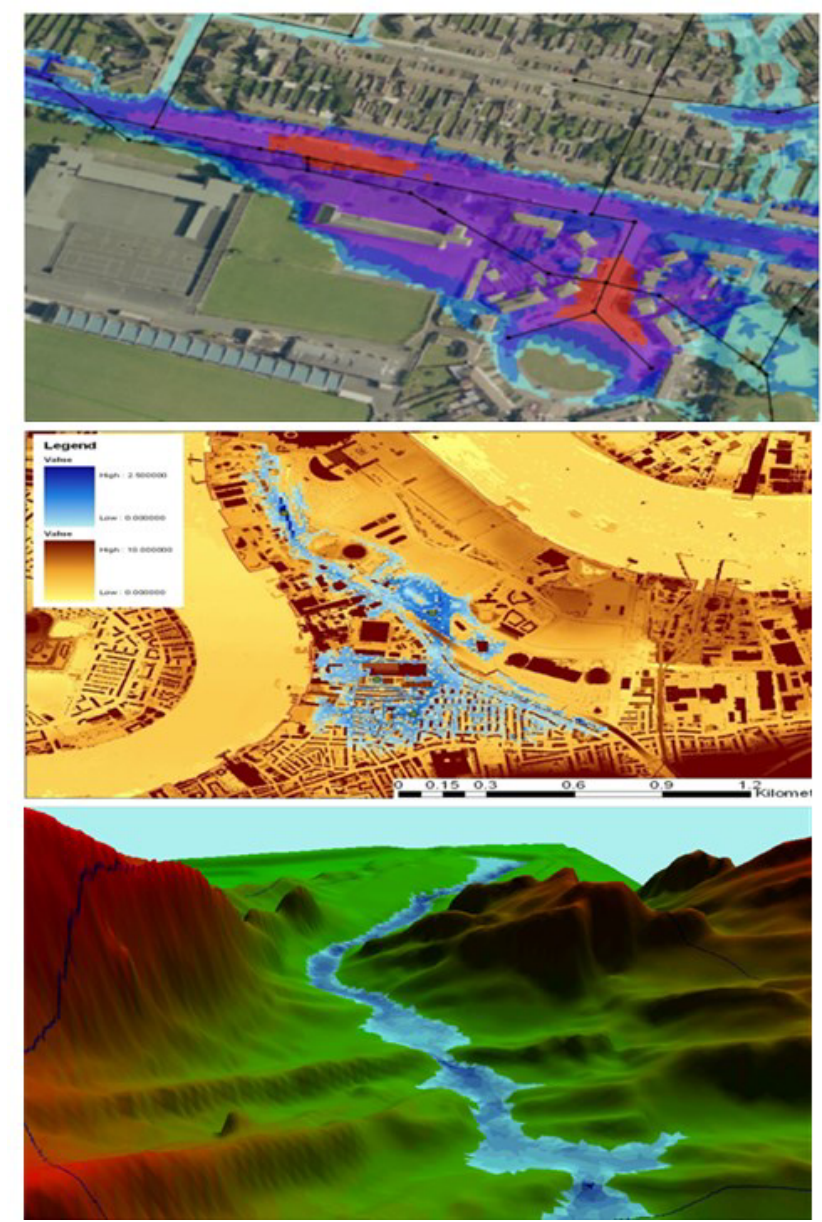

Figure 3. Outputs from flood forecasting models.

It is also possible to capture the uncertainty associated with the forecasts from the different ensemble members by overlaying the flood maps. Given the impact associated with implementing mitigation measures, including track closure, assessment of the uncertainty is critical. It is necessary to capture the uncertainty in a readily understood format, ensuring the decision-makers are appropriately supported and informed. Effective dialogue and communication between the modelling team and railway operations and asset management teams regarding the presentation of uncertainty is therefore vital.

\section{Case study set-up for Cowley Bridge}

The flood map forecasting chain described in Section 2 is to be applied to the Cowley Bridge case study, initially using off-line coupling of the models over historical flood events. The location of Cowley Bridge is presented in Figure 4 (south west corner of magnified view), and the mainline railway track comes in from the east, crossing the river several times whilst bending southwards. The map also includes the location of the upstream river gauging stations to be used for data assimilation/model validation; further details of the gauges are provided in Table 2 .

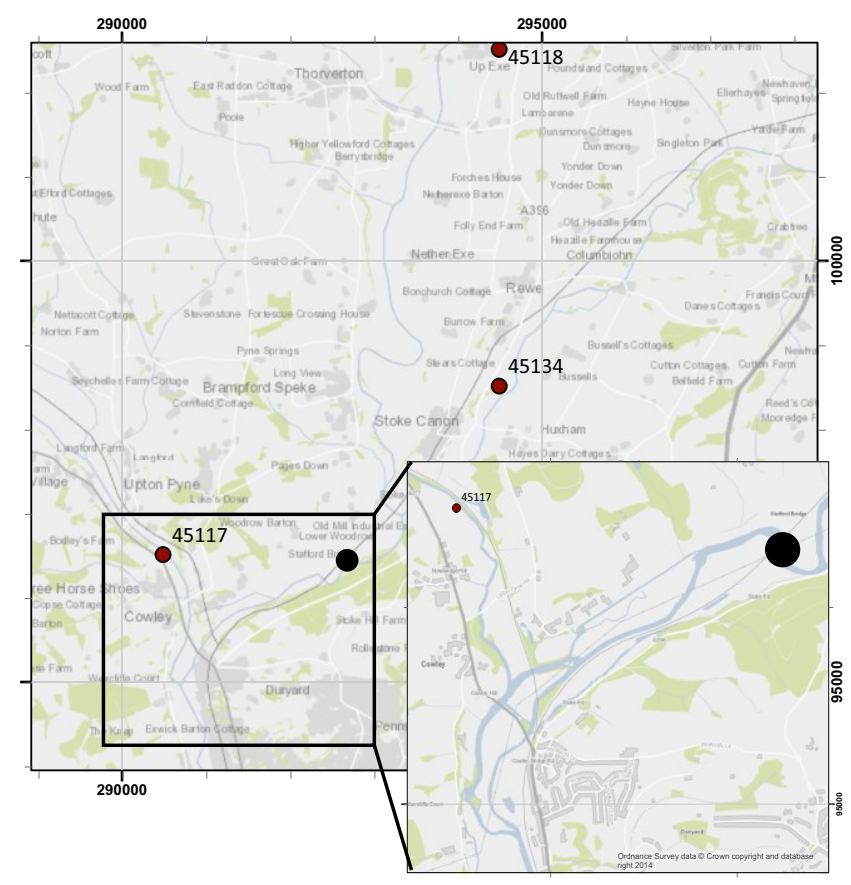

Figure 4. Map of the Cowley Bridge and surrounding area. Stafford Bridge, upstream of Cowley Bridge, is highlighted by a black dot. Red dots indicate river gauging stations.

\begin{tabular}{|l|c|}
\hline Station name (ID) & $\begin{array}{c}\text { Catchment } \\
\left.\text { Area } \mathbf{( k m}^{\mathbf{2}}\right)\end{array}$ \\
\hline Creedy at Cowley (45117) & 261.6 \\
\hline Exe at Thorverton (45118) & 600.9 \\
\hline Culm at Rewe (45134) & 275 \\
\hline
\end{tabular}

Table 2. River gauging stations upstream of Cowley Bridge.

Flood event and line closure or restriction information has been provided by Network Rail. Three recent events have been chosen for case study use: (1) 21-25 November 2012, (2) 22-23 December 2012, (3) 30 January 2013. The first two events gave rise to severe flooding at Cowley Bridge itself whilst the third event resulted in high flows at Stafford Bridge further upstream (location indicated in Figure 4). River flow hydrographs for these three events are presented in Figures 5-7 as displayed in the EA's National Flood Forecasting System.

The thresholds shown on the hydrographs are based on the $\mathrm{G} 2 \mathrm{G}$ model for the River Exe at Thorveton so are indicative of the severity of the observed flow (Thorveton has the largest flows in Figures 5-7). Note the River Culm feeds into the River Exe upstream of Cowley Bridge but downstream of the gauging station at 


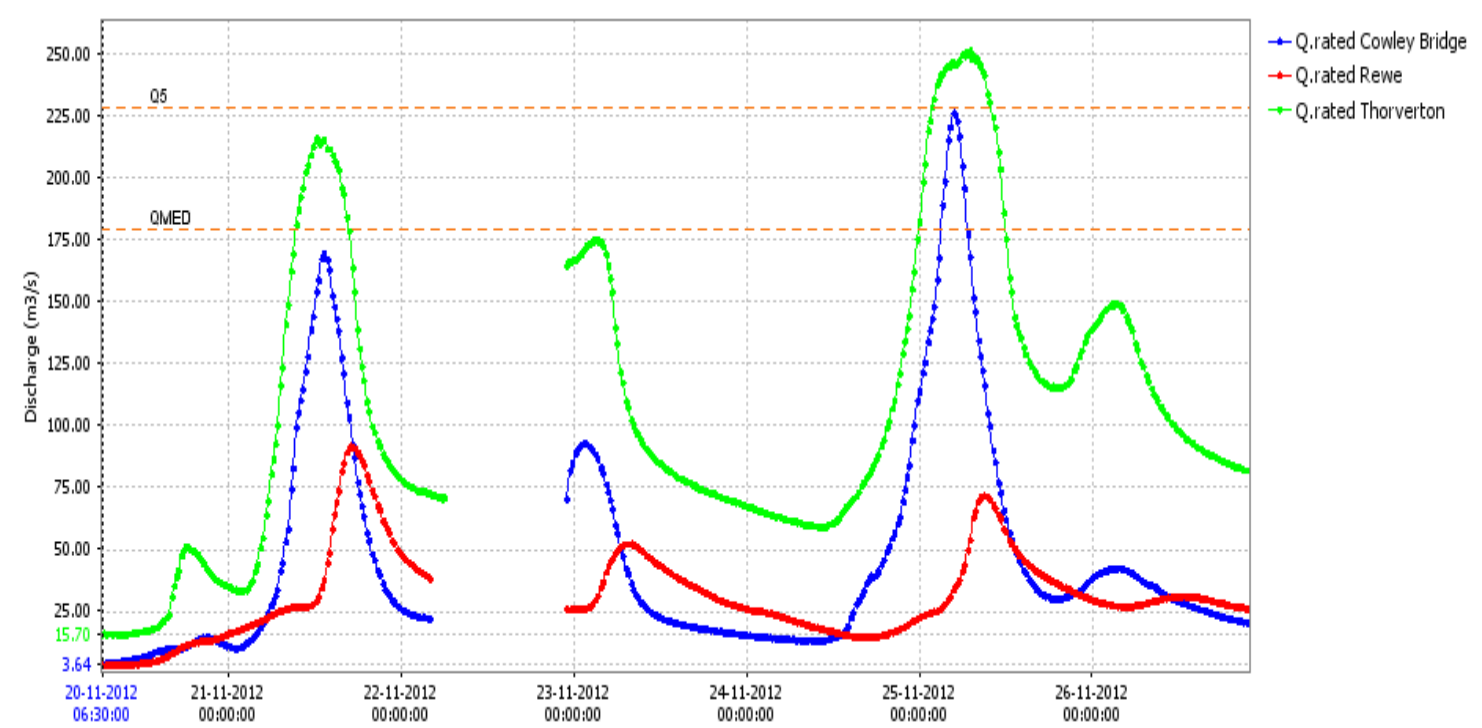

Figure 5. River flow hydrographs for the events on 21 and 25 November 2012.

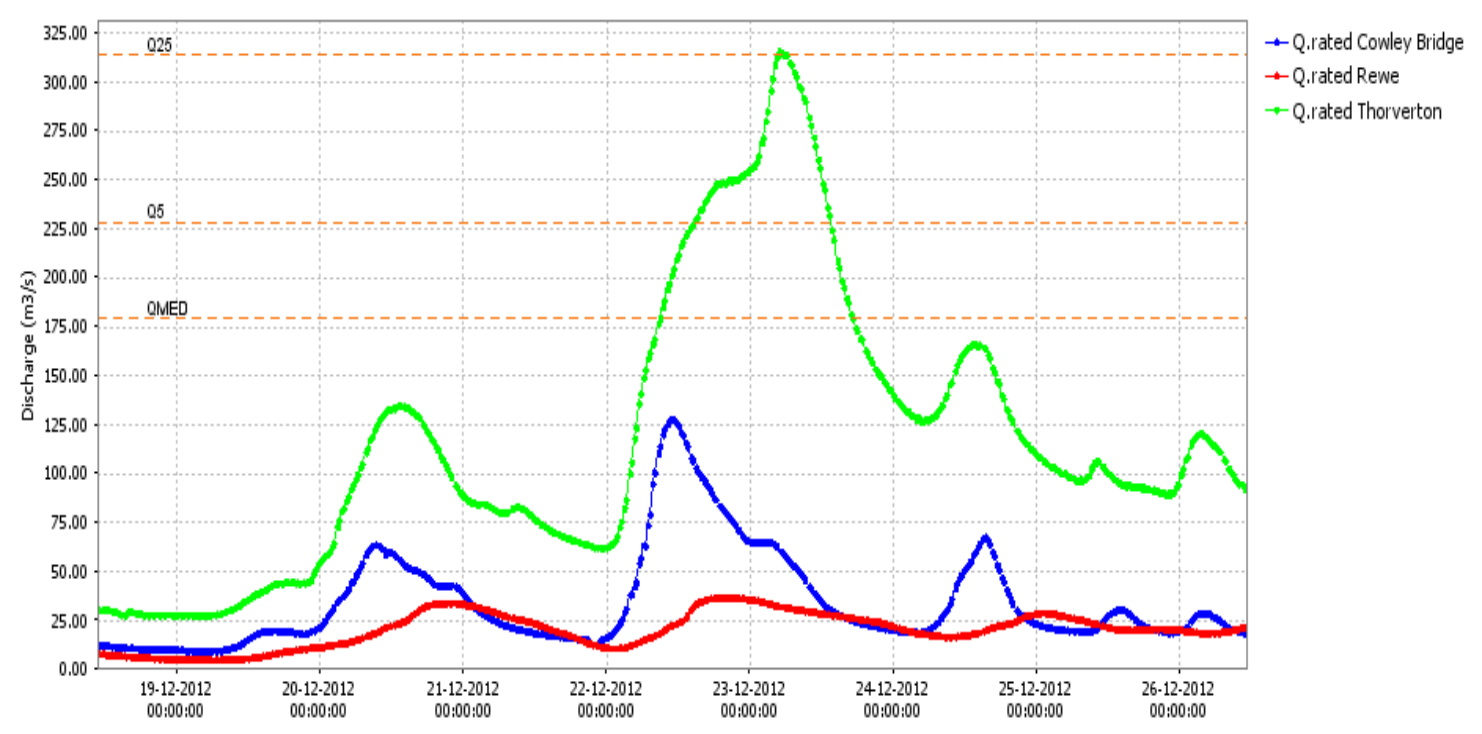

Figure 6. River flow hydrographs for the events on 22-23 December 2012.

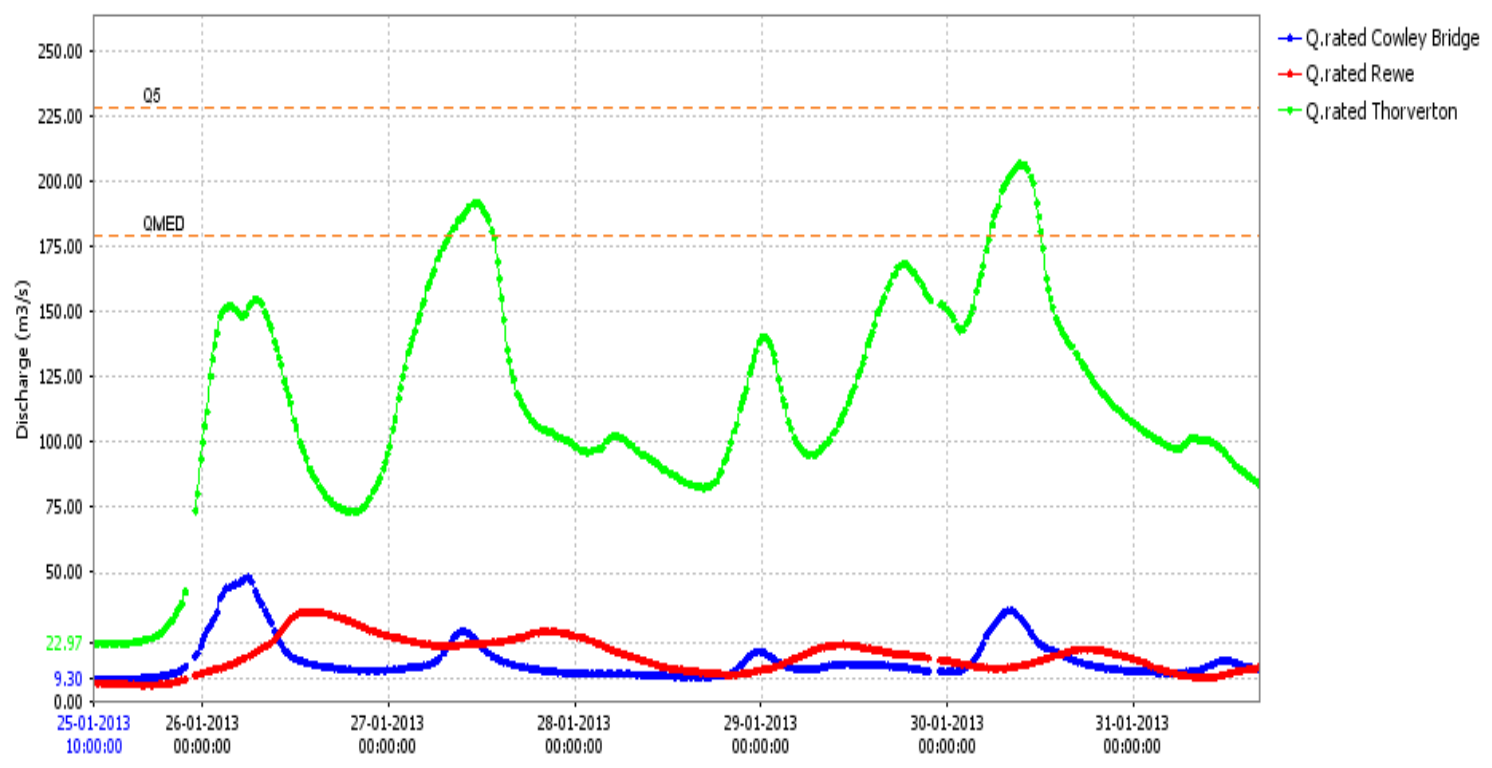

Figure 7. River flow hydrographs for the events on 30 January 2013. 
Thorverton. This gives an appreciation of the relative contribution from each of the main rivers (Exe, Creedy and Culm) during each flood.

For the 21-25 November period, the Culm and Creedy had very notable river flow responses. During the 22-23 December period the Exe river flows were more severe than those for the November period whilst flows of the Culm and Creedy were slightly less severe. The January 2013 event was less severe overall, with the River Exe having the most significant flow response whilst the Culm and Creedy were relatively minor in their response. The set of case study events encompass a wide range of spatio-temporal flood characteristics that will provide a good test of the flood mapping methodology.

\section{Future-proofing the technology}

\begin{abstract}
The design of the flood mapping forecasting chain has been developed with potential operational implementation and deployment to other sites in mind. These two points are discussed in more detail below.
\end{abstract}

\subsection{Operational implementation of the case study}

The current operational set-up used by the Flood Forecasting Centre means that the latest rainfall forecast products are already routinely coupled with the latest operational $\mathrm{G} 2 \mathrm{G}$ hydrological model with England \& Wales coverage. Therefore, any G2G boundary conditions used by the flood inundation model in the offline trial could, with agreement of the FFC, be provided as a datafeed from the Met Office to another modelling system. This has the advantage that any upgrades to the operational rainfall forecast products or G2G Model, should immediately benefit the downstream system.

The vision is that a third party would host the flood inundation modelling system and provide a web interface to the mapping outputs with automated alerts available to end users. There would be an ability for the end customer/stakeholder to configure elements of the display to meet their needs. Inundation model upgrades could also be deployed by the third party. This would remove the computational and software management burden from the IT systems of the end users but at the cost of sufficient service level agreements being in place for the service.

\subsection{Deployment of methodology to other sites}

The approach presented here has made use of existing operational rainfall and hydrological models with national coverage to facilitate deployment to other sites. If a suitable inundation model for the location of interest does not exist, one could usually be configured using standard approaches.

Before any real-time deployment, evaluation over historical events is always recommended. Historical archives of operational rainfall forecasts exist and corresponding hydrological (G2G) forecasts can be easily generated if they do not already exist. The interface to the inundation model requires more effort but techniques are improving with experience.

\section{Using sensors to support the forecasting}

\subsection{Sensors}

Operational staff can monitor for any divergence between model forecasts and observations during flood inundation events. Additionally, observations may be used to improve the $\mathrm{G} 2 \mathrm{G}$ forecasts in real-time through the data assimilation methods discussed in Section 2.2. The following discussion focuses on possible improvements to monitoring observations. Improvements can be made in three key ways:

1.By development of improved weather radar measurements and products

2. By augmentation of the existing raingauge network with one or more additional, targeted sites in the catchment

3. By use of a 'user-contributed' observation network.

\subsection{Weather radar}

The Met Office and Environment Agency jointly fund the UK Weather Radar Network. Weather radar systems provide well-maintained and widespread coverage on a $24 / 7$ basis and can capture local patterns of rainfall not seen by raingauge networks. However, the quantitative accuracy can be a shortcoming due to a range of factors such as attenuation, beam blocking, low level growth of rain below the beam associated with orographic enhancement, the effects of hydrometeor type including bright-band and so on. A full-scale radar renewal project is currently underway bringing Doppler dual-polarisation capability and is nearing completion at the time of writing. One of the anticipated benefits of the renewal project is improvements in radar-derived estimates of rainfall rates and rainfall totals.

\subsection{Extension of existing raingauge networks}

Several professionally run networks of raingauges exist in the UK. Traditionally, most gauges within these networks have been of the 'tipping bucket' type, but weighing raingauges have become increasingly costeffective in recent years and some are now in use. These weighing gauges have greater resolution and can provide a higher reporting frequency. Professional networks of this type are well run, but can be expensive due to the effort needed to calibrate, manage, and maintain the gauges. The cost of monitoring (typically for gauge blocking) and consequent unblocking action can be relatively high. Raingauge siting is considered separately below, since siting considerations are relevant to all types of raingauge. Real-time collection of rainfall data is carried out in two key ways. Firstly, raingauge installations can send 'event' data as and when each tipping bucket tip occurs. Secondly, the number of tips in 
a predetermined time can be integrated and transmitted at a specified temporal frequency.

\subsection{User contributed networks}

Recently, the Met Office has introduced a 'User contributed' weather station network. This is known as WOW (Weather Observations Website). WOW, and other systems like it, allow any user to upload weather data to the internet. These data are typically collected by relatively inexpensive automatic weather stations that are now widely available. Many of these automatic weather stations include a raingauge (usually of the tipping bucket type) and can therefore provide information on rainfall totals and intensity. Sensor sites can be set up at a typical cost of between $£ 100$ and $£ 500$. This makes local sensing quite attractive. However, it should be noted that these automatic weather stations usually require a building with internet access within a few tens of metres. As with all gauges, blockages may occur if the gauge is not checked regularly, and local ownership therefore comes with routine duties. In addition to rainfall data, the WOW network is already set-up to accept soil moisture information. This has potential to be of use in local flood inundation events, but care would be needed to co-locate raingauge and soil moisture sensors, in order to add benefit to any study.

\subsection{Exposure of raingauges}

A key consideration for ensuring accurate rainfall measurements, with any type of gauge network, is the exposure of the gauge. Gauges are best sited in level, open ground with moderate shelter from the wind, but away from large obstacles which may cause a shadowing effect and resultant under-catch. Overhanging structures or vegetation should be avoided as they can drip into the gauge. Additionally, the site should be secure and sheltered from sources of spray, such as passing trains.

\section{Conclusions}

To date, within the UK, flood forecasting systems have typically been restricted to forecasting water flow and/or level in rivers. It is not always obvious how these forecasts translate into impacts in terms of flooded properties or infrastructure. Two dimensional hydraulic models simulating flood propagation are in widespread use for flood risk analysis and mapping purposes. Increases in computational resources and technologies over the last decade has made the use of these models in real-time a possibility. This project demonstrates the potential for more directly useful information to be made available along with outputs from flood inundation models which can be supported by sensor measurements. The information can be used to support decisions relating to track closure or the implementation of mitigation measures. Given the costs of these actions, the benefits of providing more robust information to help aid the decisions is substantial.

\section{References}

1. Met Office (2016). The Met Office ensemble system (MOGREPS).

http://www.metoffice.gov.uk/research/areas/dataassimilation-and-ensembles/ensembleforecasting/MOGREPS (last accessed 22 February 2016).

2. Seed A. (2003). A dynamic and spatial scaling approach to advection forecasting. Journal of Applied Meteorology, 42, 381-388.

3. Bowler, N. E. H., Pierce, C. E. and A. W. Seed (2006). STEPS: A probabilistic precipitation forecasting scheme which merges an extrapolation nowcast with downscaled NWP. Quarterly Journal of the Royal Meteorological Society, 132, 21272155.

4. Seed, A. W., Pierce, C. E. and K. Norman (2013). Formulation and evaluation of a scale decomposition-based stochastic precipitation nowcast scheme. Water Resources Research, 49, 6624-6641.

5. Cole, S. J. and R. J. Moore (2008). Hydrological modelling using raingauge- and radar-based estimators of areal rainfall. Journal of Hydrology, 358(3-4), 159-181.

6. Moore, R. J., Jones, A. E., Jones, D. A., Black, K. B. and V. A. Bell (2004). Weather radar for flood forecasting: some UK experiences. 6th International Symposium on Hydrological Applications of Weather Radar, 2-4 February 2004, Melbourne, Australia, $11 \mathrm{pp}$.

7. Tang, Y., Lean, H.W. and J. Bornemann (2013). The benefits of the Met Office variable resolution NWP model for forecasting convection. Meteorological Applications, 20, 417-426.

8. Moore, R. J., Cole, S. J., Bell, V. A. and D. A. Jones (2006). Issues in flood forecasting: ungauged basins, extreme floods and uncertainty. In: I. Tchiguirinskaia, K. N. N. Thein \& P. Hubert (eds.), Frontiers in Flood Research, 8th Kovacs Colloquium, UNESCO, Paris, June/July 2006, IAHS Publication 305, 103-122.

9. Bell, V. A., Kay, A. L., Jones, R. G., Moore, R. J. and N. S. Reynard (2009). Use of soil data in a gridbased hydrological model to estimate spatial variation in changing flood risk across the UK. Journal of Hydrology, 377, 335-350.

10. Cole, S.J. and R. J. Moore (2009). Distributed hydrological modelling using weather radar in gauged and ungauged basins. Advances in Water Resources, 32, 1107-1120.

11. Price, D., Hudson, K., Boyce, G., Schellekens, J., Moore, R.J., Clark, P., Harrison, T., Connolly, E. and C. Pilling (2012). Operational use of a grid-based model for flood forecasting. Water Management, 165(2), 65-77.

12. Cranston, M., Maxey, R., Tavendale, A., Buchanan, P., Motion, A., Cole, S., Robson, A., Moore, R.J. and A. Minett (2012). Countrywide flood forecasting in Scotland: challenges for hydrometeorological model 
uncertainty and prediction. In: Weather Radar and Hydrology (ed. by R. J. Moore, S. J. Cole \& A. J. Illingworth) (Proceedings Exeter Symposium, April 2011), IAHS Publication 351, 538-542.

13. Cole, S. J., Moore, R. J., Robson, A. J., Mattingley, P. S., Black, K. B. and A. L. Kay (2014). Evaluating G2G for use in Rapid Response Catchments: Final Report. R\&D Project Report SC110003/R1, Joint Defra/EA Flood and Coastal Erosion Risk Management, Research Contractor: CEH Wallingford, $115 \mathrm{pp}$. 